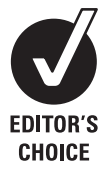

See Commentaries, pages 3 and 5

${ }^{1}$ Division of Occupational and Environmental Medicine, Department of Public Health

Sciences Karolinska Institutet, Stockholm, Sweden;

${ }^{2}$ Occupational and

Environmental Medicine,

Department of Medical

Sciences, Uppsala University,

Uppsala, Sweden; ${ }^{3}$ Department

of Neurobiology, Care Sciences and Society, Karolinska

Institutet, Stockholm, Sweden;

${ }^{4}$ Department of Economic

History, Uppsala University,

Uppsala, Sweden

Correspondence to:

Mr A Lundin, Division of

Occupational and Environmental Medicine, Department of Public

Health Sciences, Karolinska

Institutet, Norrbacka plan 5, 171

76 Stockholm, Sweden;

andreas.lundin@ki.se

Accepted 11 February 2009

Published Online First

15 March 2009

\title{
Unemployment and mortality-a longitudinal prospective study on selection and causation in 49321 Swedish middle-aged men
}

\author{
A Lundin, ${ }^{1}$ I Lundberg, ${ }^{2}$ L Hallsten, ${ }^{3}$ J Ottosson, ${ }^{4}$ T Hemmingsson'
}

\section{ABSTRACT}

Background: Unemployment is associated with increased risk of mortality. It is, however, not clear to what extent this is causal, or whether other risk factors remain uncontrolled for. The aim of this study was to investigate the association between unemployment and all-cause and cause-specific mortality, adjusting for indicators of mental disorder, behavioural risk factors and social factors over the life course.

Methods: This study was based on a cohort of 49321 Swedish males, born 1949/51, tested for compulsory military conscription in 1969/70. Data on employment/ unemployment 1990-4 was based on information from the Longitudinal Register of Education and Labour Market Statistics. Information on childhood circumstances was drawn from National Population and Housing Census 1960. Information on psychiatric diagnosis and behavioral risk factors was collected at conscription testing in 1969/ 70. Data on mortality and hospitalisation 1973-2004 were collected in national registers.

Results: An increased risk of mortality 1995-2003 was found among individuals who experienced 90 days or more of unemployment during 1992-4 compared with those still employed (all-cause mortality HR 1.91, 95\% Cl 1.58 to 2.31. Adjustment for risk factors measured along the life course considerably lowered the relative risk (all cause mortality HR $1.30,95 \% \mathrm{Cl} 1.06$ to 1.58 ).

Statistically significant increased relative risk was found during the first 4 years of follow up (all-cause mortality, adjusted HR 1.57, 95\% $\mathrm{Cl} 1.13$ to 2.18, but not the following 4 years (all cause mortality, adjusted HR 1.17, 95\% Cl 0.91 to 1.50).

Conclusion: The results suggest that a substantial part of the increased relative risk of mortality associated with unemployment may be attributable to confounding by individual risk factors.

Many studies have reported excess mortality in men and women who have experienced unemployment. Unemployment is suggested to be associated with an increased risk of mortality from all causes, ${ }^{1-9}$ suicide, ${ }^{2368-13}$ death in undetermined causes $^{2689}$ and mortality from cardiovascular disease (CVD). ${ }^{36} 812$ Suggested causal mechanisms include financial strain, ${ }^{14-16}$ psychological stress ${ }^{14} 15$ and changed health-related behaviour. ${ }^{14}{ }^{17-19}$ It is, however, not clear if the relation between unemployment and later mortality found in previous studies is causal. The increased relative risk of mortality among the unemployed could, at least partly, be a consequence of health-related selection. Those who are ill (direct selection), or exposed to risk factors for illness (indirect selection), may be more likely to lose their jobs and find it harder to regain employment.

Several studies have adjusted mortality risks of unemployment for previous health status ${ }^{136711} 12$ and risk behaviours, ${ }^{378}$ while only a few studies have adjusted for mental disorder and personality characteristics. ${ }^{1820}$ In a 3-year follow-up of the New Zealand 1991 census, Blakely and colleagues ${ }^{10}$ found a relative risk of suicide among those unemployed compared with those employed of 2.5. A sensitivity analysis based on prevalence of mental disorder in the community, assessed that about half of the excess risk could be due to mental disorder. A Finnish cross-lagged study showed that among male healthcare workers belonging to the workforce and with no unemployment 1988-9, becoming hospitalised with a psychiatric diagnosis in 1996-9 was associated with a strong relative risk (OR 2.5) of subsequent unemployment (2000-2). ${ }^{21}$ Studies have also shown that, for instance, personality characteristics early in life are related to later periods of unemployment. ${ }^{22} 23$

A Swedish 12-year follow-up study on mortality in all employees displaced due to closures in the Swedish private sector in 1987-8 included control for a wide range of health indicators, measured up to 4 years before job loss. ${ }^{12}$ An excess risk of mortality, mainly from suicide and CVD was found during the first 4 years of follow-up, which then declined in the following years. It has been suggested that an increased risk associated with unemployment during the first years but not later would indicate health selection to unemployment due to illness. ${ }^{2} 5$

The present study was based on a population of almost 50000 Swedish men born 1949-51. Sweden underwent a period of rapidly increasing unemployment during 1992-4. After three decades of average unemployment figures of around $2 \%$, Sweden experienced levels of $8.2 \%$ in 1993, starting from $1.5 \%$ in 1990 , when the Swedish slump started. ${ }^{24}$

The aim of the study was to investigate the association between becoming unemployed and subsequent mortality, adjusting for risk factors for mortality over the life course. The following research questions were thus asked: Is there an excess risk of mortality following exposure to unemployment 1992-4? To what extent may the association between unemployment and mortality be explained by risk factors preceding unemployment?

\section{SUBJECTS AND METHODS}

This study was based on 49321 Swedish men examined for compulsory military service in 196970. At this time only $2-3 \%$ of Swedish young men 
were exempted from conscription, in most cases due to severe handicaps or congenital disorder. The study encompasses those men born 1949 (5\%), 1950 (18\%) and 1951 (77\%), which represent $97.7 \%$ of all conscripts $1969-70$; the $2.3 \%$ of the conscripts 1969-70 who were born before 1949 were excluded.

The study combined data from various register data provided by Statistics Sweden (table 1). By combining conscription data, the Swedish National Population and Housing Censuses 1960 and 1990, the Swedish Hospital Discharge Register 1973-91 and the Longitudinal Register of Education and Labour Market Statistics (LOUISE), for each individual in the cohort, it is possible to study a number of individual risk factors. Ethical approval for using the anonymised database was granted by the Karolinska Institute Research Ethics Committee and the Swedish Data Inspection Board.

\section{DATA FROM THE CONSCRIPTION EXAMINATION IN 1969}

The examination consisted of a physical examination, interview by a psychologist and two survey questionnaires. The first questionnaire concerned social background, behaviour and adjustment, psychological factors and health, while the second questionnaire addressed substance use. After the interview, the psychologist combined the interview data and questionnaires into ratings of emotional control. Conscripts with symptoms of, or self-reported psychiatric disorder, were examined by a psychiatrist, and any mental disorders were recorded in accordance with International Classification of Disease, revision 8 (ICD-8).

The following variables measured at the conscription examination in 1969 were included in the analysis as potential confounders in the unemployment-mortality association: being diagnosed with a mental disorder by psychiatrist; being rated by psychologist as having low emotional control (suffering from reduced functions due to psychosomatic symptoms, low stress tolerance, and/or full of anxiety, problems controlling nervousness and aggression, and incapacity for emotional commitment, corresponding to the lowest $20 \%$ in a Gaussian distribution of general emotional control); risk use of alcohol (experience of being apprehended for drunkenness; or using alcohol as 'hair of the dog'; or been drunk often/quite often; or reported alcohol consumption of at least $250 \mathrm{~g} /$ week); smoking (>5 cigarettes/day); and having been in contact with police or childcare authorities. ${ }^{25}$

\section{DATA ON CHILDHOOD SOCIAL CIRCUMSTANCES}

Childhood social circumstances, including crowded housing $(>2$ people/room-kitchen not included), was obtained from the Swedish National Population and Housing Census 1960 (ie, at age 9-11) of the conscripts' parents, or other head of the household, through their unique personal identification number. Classification into socioeconomic groups was based on information on occupation and general level of education required for that occupation: (i) unskilled workers; (ii) skilled workers; (iii) assistant non-manual employees; (iv) non-manual employees at intermediate level; (v) non-manual employees at higher level; (vi) farmers; and (vii) those not classified in a socioeconomic group.

\section{PSYCHIATRIC DIAGNOSES 1973-91}

Information on psychiatric diagnoses was obtained from the Swedish Hospital Discharge Register 1973-91, ie, at ages 22-42. The following diagnoses were included: mental disorder (ICD-8 290-309, ICD-9 290-313, ICD-10 F00-F69), self-inflicted harm (ICD-8 and ICD-9 E95 and E98, ICD-10 X60-X84 and Y10-Y34) and alcohol disorders/injuries (ICD-8 291, 303 and 980, ICD-9 303, 305A, 980, 571A, 571B, 571C, 571D and 291W, ICD-10 F100-F103, T51 and K70).

\section{DATA ON ADULT SOCIOECONOMIC POSITION AND SICKNESS ABSENCE}

Information on three measures of socioeconomic position prior to unemployment was used: educational attainment, occupational class and income. Information on occupational class was obtained from the National Population and Housing Censuses 1990, and classification was made as described for childhood socioeconomic circumstances above. Educational attainment from 1990 was obtained from the Longitudinal Register of Education and Labour Market Statistics (LOUISE), and classified as completion of 9 or less years, 11 years, 12 years and more than 12 years of education. Information on income was obtained from the same register, and calculated as quintiles of the average amount of income from employment and business for the combined years 1990-1.

Information on sickness absence was obtained from LOUISE, as total received amount of benefits from national health insurance 1990-1, and grouped as non-recipients, low-recipients

Table 1 Data collection 1949-2003

\begin{tabular}{|c|c|c|c|}
\hline & Calendar year & Age of subject & \\
\hline Birth years & $1949-51$ & 0 & \\
\hline $\begin{array}{l}\text { National Population and Housing } \\
\text { Censuses } 1960\end{array}$ & 1960 & $9-11$ & $\begin{array}{l}\text { Information on childhood socioeconomic position } \\
\text { and on crowded housing was collected from } \\
\text { information given by the father or other head of } \\
\text { household }\end{array}$ \\
\hline Conscription examination & 1969 & $18-20$ & $\begin{array}{l}\text { Information on psychiatric diagnosis, risk use of } \\
\text { alcohol, smoking, emotional control and contact } \\
\text { with police or childcare authorities }\end{array}$ \\
\hline $\begin{array}{l}\text { National Hospital Discharge } \\
\text { Register 1973-91 }\end{array}$ & 1973-91 & $22-42$ & $\begin{array}{l}\text { Information on hospitalisation with a psychiatric } \\
\text { diagnosis, alcoholism or suicide attempt }\end{array}$ \\
\hline $\begin{array}{l}\text { National Population and Housing } \\
\text { Censuses } 1990\end{array}$ & 1990 & $39-41$ & $\begin{array}{l}\text { Information on education and socioeconomic } \\
\text { position }\end{array}$ \\
\hline $\begin{array}{l}\text { Longitudinal Register of Education } \\
\text { and Labour Market Statistics } \\
1990-1\end{array}$ & $1990-1$ & $39-42$ & $\begin{array}{l}\text { Information on employment, unemployment, } \\
\text { sickness absence, early retirement and income }\end{array}$ \\
\hline $\begin{array}{l}\text { Longitudinal Register of Education } \\
\text { and Labour Market Statistics } \\
\text { 1992-4 }\end{array}$ & $1992-4$ & $41-45$ & Information on unemployment \\
\hline $\begin{array}{l}\text { Swedish Cause of Death } \\
\text { Registers 1995-2003 }\end{array}$ & 1995-2003 & $44-54$ & Information on cause and time of death \\
\hline
\end{tabular}


(3600-8200 SEK), medium recipients (8300-24 500 SEK), and high recipients ( $>24600$ SEK) of benefits during 1990-1 (exchange rate average 1990: SEK $100=$ US\$ 59.1).

\section{DATA ON LABOUR MARKET PARTICIPATION}

Only those gainfully employed during 1990 and 1991, defined as having yearly income from work exceeding 50000 SEK, were included in the study. Information on work-related income was obtained from the LOUISE database for these years. This register contains information for every individual in Sweden aged 16-64, regarding income, labour market status, education, age, sex and family conditions, from 1990 onwards (Statistics Sweden). Individuals receiving early retirement 1990-2 were excluded from the study population.

\section{DATA ON UNEMPLOYMENT}

In the LOUISE database, information on individual yearly unemployment is registered. Unemployment exposure groups were classified into those with 1-89 days and those with 90 or more days of accumulated registered unemployment 1992-4. Registration is a necessary condition for both being eligible for unemployment benefits, as well as participation in any labour market programmes. To receive benefits, one must be registered at a labour office as at least partly lacking employment, and being in a position to accept any offered jobs. Register data on the amount of employment and unemployment in the years before and during the Swedish crisis provide a very accurate measure of unemployment following job loss.

\section{INFORMATION ON OUTCOMES}

Information on cause of and age at death was obtained from the National Cause of Death Register from the beginning of 1995 to the end 2003. Besides all-cause mortality, the following outcomes were studied: mortality from external cause (ICD-9 E80-E99, ICD-10 V, X and Y), with separate analysis for suicide (ICD-9 E95 and E98, ICD-10 X60-X84 and Y10-Y34) and mortality from external cause other than suicide (ICD-9 E810-E830, ICD-10 V01-Y98); and mortality from diseases (all mortality excluding that from external cause), including a separate analysis for CVD mortality (ICD-9 340-459, ICD-10 I01-I98).

\section{DATA ANALYSIS}

Subjects still alive in 1995 and who were gainfully employed in 1990 and 1991 (annual work-related income above 50000 SEK) were included in the study. All recipients of early retirement pension (which is a disability pension) before 1993 were excluded, as well as all individuals receiving unemployment benefits of any amount for 1990-1. The association between exposure to unemployment 1992-4 and mortality 1995-2003 was investigated by means of crude and multivariate Cox proportional hazard models, using the PHREG procedure in the SAS statistical package (version 9.1). Confounding variables were included individually, as well as grouped according to order of appearance in the life course. In order to investigate the hypothesis of wear off of selection, we also used two follow-up periods, 1995-8 and 1999-2003. A separate analysis was also carried out for all-cause mortality 1995-6 and 1997-8. The proportion of the association explained by confounding was calculated as ((HRcrude - HRadjusted)/(HRcrude - 1)).

\section{RESULTS}

Table 2 shows an outline for inclusion in the study. A total of 37798 individuals were included in the final analysis, of whom $14.3 \%$ experienced unemployment 1992-4. In total $11.3 \%$ experienced 90 days or more of unemployment.

\section{Prevalence of antecedent risk factors among the employed/ unemployed}

Table 3 shows the prevalence of each potential explanatory variable among those exposed to any unemployment and among those who remain in full employment for 1992-4. The table also shows the prevalence of each risk factor among those not included in the analysis, that is, those who died before start of follow-up 1995, and among those not meeting our criteria to be regarded as stably employed 1990-1.

The prevalence of each risk factor was higher among individuals exposed to unemployment for 1-89 days in 1992-4 than among those not exposed, and even higher among those with 90 days or more of unemployment in 1992-4. Among those not included in the analysis, the prevalence of almost all risk factors measured at conscription, as well as psychiatric diagnosis 1973-91, were substantially higher than among those stably employed 1990-1, for example, prevalence of psychiatric diagnosis 1973-91 was five to ten times more common among those not included in the analysis than in those in stable employment 1990-1.

Table 4 shows the association between each potential risk factor and all-cause and cause-specific mortality. All risk factors except childhood social class are significantly associated with all-cause mortality and with most other outcomes. Childhood social class is significantly associated with mortality from CVD.

\section{Unemployment and mortality}

Table 5 shows the association between 90 days or more of unemployment 1992-4 and mortality 1995-2003 as hazard ratios calculated with $95 \%$ CIs. The reference group is those with no unemployment $1992-4$. No increased relative risks were found for those with 1-90 days of unemployment (data not shown).

In the crude analysis, unemployment was significantly associated with all outcomes, with relative risks between 1.72 and 2.78. The relative risk for all cause mortality was 1.91 (1.58 to 2.31 ). In the multivariate analysis, risk factors were added to the model, first individually and then in order of their appearance in the life course grouped as (a) childhood social circumstances and adolescence behaviour and characteristics; (b) psychiatric diagnosis between 1973 and 1991; and (c) socioeconomic position and sickness absence adjacent to unemployment. All risk factors have a reducing effect on the hazard ratios. The single factor that contributed to the strongest reduction of the hazard ratios from the crude analysis was sickness absence during 1990-1. With all risk factors included, the excess risks 1995-2003 in the crude analysis were reduced for all outcomes by between $54 \%$ and $89 \%$. We also

Table 2 Description of the cohort

\begin{tabular}{|c|c|}
\hline Full cohort & 49321 \\
\hline Number alive at beginning of follow-up period 1995 & 47944 \\
\hline Number with no early retirement benefits before 1993 & 46861 \\
\hline $\begin{array}{l}\text { Number with yearly earnings exceeding } 50000 \text { SEK for } 1990 \\
\text { and } 1991\end{array}$ & 42150 \\
\hline $\begin{array}{l}\text { Number with no exposure to unemployment } 1990-1 \text {, ie those } \\
\text { stably employed }\end{array}$ & 40150 \\
\hline $\begin{array}{l}\text { Stably employed with information on all variables included in } \\
\text { table } 3\end{array}$ & 37798 \\
\hline
\end{tabular}


Table 3 Proportion (\%) of individuals exposed to potential explanatory variables in groups with different labour market experiences

\begin{tabular}{|c|c|c|c|c|c|}
\hline \multirow[b]{3}{*}{ Explanatory variables } & \multicolumn{5}{|l|}{ Cohort } \\
\hline & \multicolumn{3}{|c|}{$\begin{array}{l}\text { Stably employed and included in the analysis } \\
(\mathrm{n}=37798)^{*}\end{array}$} & \multicolumn{2}{|c|}{$\begin{array}{l}\text { Not included in the analysis } \\
(\mathrm{n}=9171)\end{array}$} \\
\hline & $\begin{array}{l}\text { Not } \\
\text { unemployed } \\
\text { 1992-4 } \\
(\mathrm{n}=32388)\end{array}$ & $\begin{array}{l}\text { Unemployed 1- } \\
89 \text { days 1992-4 } \\
\text { ( } \mathrm{n}=1147)\end{array}$ & $\begin{array}{l}\text { Unemployed }> \\
89 \text { days } 1992-4 \\
(n=4263)\end{array}$ & $\begin{array}{l}\text { Not stably } \\
\text { employed } \\
1990-1 \\
(n=7794)\end{array}$ & $\begin{array}{l}\text { Not alive } 1995 \\
\text { ( } \mathrm{n}=1377)\end{array}$ \\
\hline $\begin{array}{l}\text { Crowded housing during upbringing } \\
1960\end{array}$ & 18.7 & 22.8 & 25.4 & 23.1 & 24.8 \\
\hline Father manual worker 1960 & 53.4 & 58.4 & 61.3 & 54.9 & 57.5 \\
\hline Risk use of alcohol 1969 & 10.8 & 14.3 & 17.8 & 20.5 & 26.2 \\
\hline Smoking 1969 & 44.1 & 51.3 & 55.1 & 55.7 & 59.2 \\
\hline $\begin{array}{l}\text { Psychiatric diagnosis at conscription } \\
1969\end{array}$ & 9.70 & 12.5 & 14.4 & 20.7 & 23.8 \\
\hline Low emotional control 1969 & 26.7 & 30.6 & 33.5 & 40.8 & 44.4 \\
\hline $\begin{array}{l}\text { Contact with police or childcare } \\
\text { authorities } 1969\end{array}$ & 25.0 & 31.1 & 35.8 & 38.5 & 45.0 \\
\hline Psychiatric diagnosis 1973-91 & 3.0 & 5.1 & 7.2 & 17.0 & 30.9 \\
\hline Manual worker 1990 & 40.3 & 55.1 & 60.1 & & \\
\hline Basic education up to 9 years 1990 & 23.0 & 32.2 & 34.4 & & \\
\hline $\begin{array}{l}\text { Lowest quintile of obtained income } \\
1990-1\end{array}$ & 17.9 & 28.9 & 33.8 & & \\
\hline Sickness absence $>24500$ 1990-1 & 8.3 & 15.3 & 21.7 & & \\
\hline
\end{tabular}

${ }^{*} A$ total of 2352 were excluded because of incomplete data.

divided all risk factors into two groups: indicators of direct selection (psychiatric diagnosis 1969 and 1973-91 and sickness absence 1990-1) and indicators of indirect selection (all other variables). When adjusting the association between unemployment and all-cause mortality for direct and indirect health selection, respectively, the relative risk found in the crude analysis was reduced equally as much, that is, $49 \%$, in both analyses.

Table 4 Association between each potential risk factor and all-cause and cause-specific mortality 1995-2003

\begin{tabular}{|c|c|c|c|c|c|c|}
\hline & $\begin{array}{l}\text { All-cause mortality } \\
(\mathrm{n}=694)\end{array}$ & $\begin{array}{l}\text { Violent death } \\
(\mathrm{n}=135)\end{array}$ & Suicide $(n=90)$ & $\begin{array}{l}\text { Violent death other } \\
\text { than suicide }(n=45)\end{array}$ & $\begin{array}{l}\text { Non-violent death } \\
\text { (n= 559) }\end{array}$ & CVD $(n=232)$ \\
\hline & HR $(95 \% \mathrm{CI})$ & HR (95\% CI) & HR $(95 \%$ CI) & HR $(95 \% \mathrm{CI})$ & HR $(95 \% \mathrm{CI})$ & HR $(95 \% \mathrm{CI})$ \\
\hline $\begin{array}{l}\text { Crowded housing } \\
1960\end{array}$ & 1.31 (1.10 to 1.56$)$ & 1.55 (1.06 to 2.27$)$ & $1.58(1.00$ to 2.51$)$ & $1.50(0.77$ to 2.90$)$ & $1.26(1.04$ to 1.53$)$ & 1.37 (1.02 to 1.85$)$ \\
\hline $\begin{array}{l}\text { Father unskilled } \\
\text { worker } 1960 \text { (ref } \\
=\text { intermediate and } \\
\text { high non-manual } \\
\text { worker 1960) }\end{array}$ & $1.15(0.93$ to 1.41$)$ & $1.10(0.67$ to 1.79$)$ & $1.02(0.56$ to 1.85$)$ & $1.27(0.54$ to 3.01$)$ & $1.16(0.92$ to 1.45$)$ & 1.81 (1.24 to 2.66$)$ \\
\hline $\begin{array}{l}\text { Risk use of alcohol } \\
1969\end{array}$ & 1.64 (1.35 to 1.99$)$ & $1.90(1.24$ to 2.89$)$ & 1.52 (0.87 to 2.64$)$ & $2.76(1.43$ to 5.35$)$ & $1.58(1.27$ to 1.96$)$ & 1.98 (1.44 to 2.73$)$ \\
\hline Smoking 1969 & 1.59 (1.37 to 1.84$)$ & 1.55 (1.10 to 2.17$)$ & 1.25 (0.83 to 1.90$)$ & $2.40(1.29$ to 4.46$)$ & $1.60(1.35$ to 1.89$)$ & 2.16 (1.65 to 2.82$)$ \\
\hline $\begin{array}{l}\text { Psychiatric } \\
\text { diagnosis } 1969\end{array}$ & $1.49(1.20$ to 1.84$)$ & $2.28(1.51$ to 3.46$)$ & $2.18(1.30$ to 3.66$)$ & $2.49(1.24$ to 5.04$)$ & $1.31(1.03$ to 1.68$)$ & $1.40(0.96$ to 2.03$)$ \\
\hline $\begin{array}{l}\text { Low emotional } \\
\text { control } 1969\end{array}$ & 1.36 (1.16 to 1.59$)$ & $1.70(1.20$ to 2.40$)$ & 1.67 (1.09 to 2.55$)$ & $1.75(0.96$ to 3.18$)$ & 1.29 (1.08 to 1.54$)$ & $1.33(1.01$ to 1.75$)$ \\
\hline $\begin{array}{l}\text { Police/childcare } \\
\text { contact } 1969\end{array}$ & $1.54(1.32$ to 1.80$)$ & 2.05 (1.46 to 2.88$)$ & $1.55(1.00$ to 2.38$)$ & $3.50(1.95$ to 6.31$)$ & $1.43(1.20$ to 1.71$)$ & $1.68(1.29$ to 2.20$)$ \\
\hline $\begin{array}{l}\text { Unskilled worker } \\
1990 \text { (ref = } \\
\text { intermediate and } \\
\text { high non-manual } \\
\text { worker 1990) }\end{array}$ & 1.70 (1.40 to 2.07$)$ & 1.76 (1.14 to 2.70$)$ & 2.00 (1.14 to 3.52$)$ & $1.45(0.74$ to 2.85$)$ & 1.69 (1.36 to 2.10$)$ & 1.90 (1.35 to 2.68$)$ \\
\hline $\begin{array}{l}\text { Education }<9 \text { years } \\
\text { (ref }>12 \text { years' } \\
\text { education) }\end{array}$ & 1.96 (1.59 to 2.41$)$ & $2.23(1.40$ to 3.58$)$ & 2.39 (1.33 to 4.29$)$ & $1.97(0.89$ to 4.34$)$ & $1.89(1.50$ to 2.39$)$ & 2.37 (1.61 to 3.49 ) \\
\hline $\begin{array}{l}\text { 1st income quintile } \\
1990-1 \text { (ref = 5th } \\
\text { quintile income) }\end{array}$ & 2.87 (2.25 to 3.66$)$ & $2.89(1.61$ to 5.20$)$ & 2.44 (1.24 to 4.77$)$ & 4.71 (1.35 to 16.37$)$ & $2.86(2.19$ to 3.75$)$ & 3.95 (2.47 to 6.31$)$ \\
\hline $\begin{array}{l}\text { Sickness absence } \\
>245001990-1 \\
\text { (ref }=\text { no sickness } \\
\text { absence) }\end{array}$ & 3.12 (2.57 to 3.80$)$ & $3.99(2.55$ to 6.26$)$ & 3.70 (2.14 to 6.42$)$ & $4.66(2.13$ to 10.22$)$ & 2.96 (2.38 to 3.67$)$ & 3.52 (2.53 to 4.91$)$ \\
\hline
\end{tabular}

Values in bold represent the attenuation of the hazard ratio. 
Table 5 Association between unemployment $>89$ days and all-cause and cause-specific mortality 1995-2003

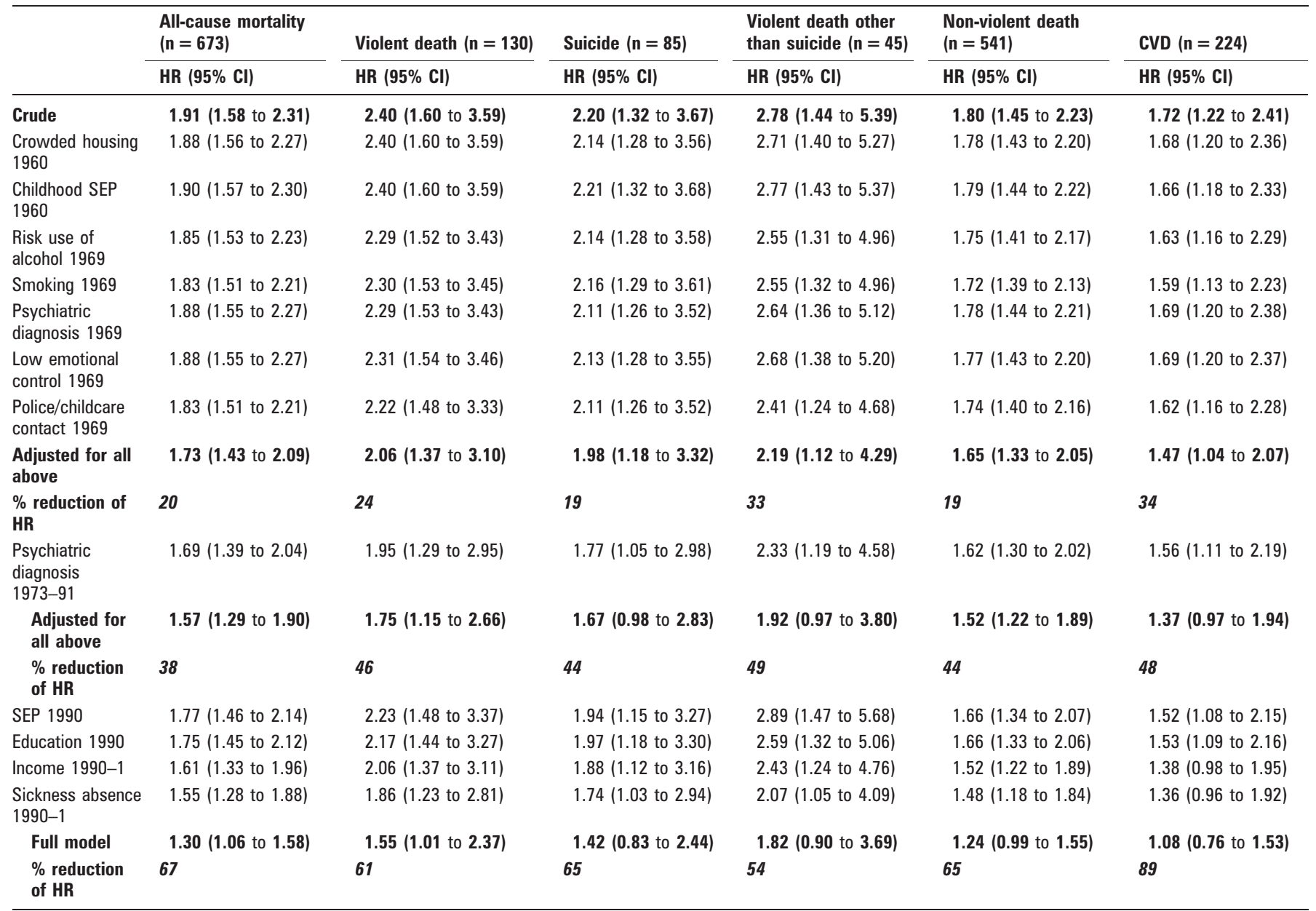

Crude and adjusted hazard ratios (HR) with 95\% Cls. CVD, cardiovascular disease; SEP, socioeconomic position.

Values in bold and italic represent the attenuation of the hazard ratio.

Table 6 shows the association between exposure to 90 days or more of unemployment 1992-4 and mortality during 1995-8 and 1999-2003 compared with those with no unemployment 1992-4.

This table shows that relative risks were more pronounced in the first period, with significant, high, crude risks for all outcomes except CVD associated with 90 days or more unemployment. Controlling for confounders explained between $32 \%$ and $81 \%$ in the first period, with remaining significant relative risks of all-cause mortality, mortality from external cause and its subcategory violent death other than suicide. In the latter period, the association between 90 days or more of unemployment and mortality was weaker, and significantly increased only for all-cause mortality and natural death and mortality from CVD. After adjustment for all risk factors, relative risks were reduced with $72-100 \%$ from the relative risks found in the crude analysis, and no statistical significance remained. A separate analysis on the association between exposure to 90 days or more of unemployment 1992-4 and mortality during 1995-6 $(\mathrm{n}=102)$ and 1997-8 $(\mathrm{n}=120)$, showed a crude hazard ratio of 2.34 (1.48 to 3.70) in the first period, and 2.43 (1.60 to 3.70) in the latter. In the full model, the hazard ratios were 1.61 (0.99 to 2.62) and 1.53 (0.99 to 2.39), respectively.

Table 6 Association between unemployment $>89$ days and all-cause and cause-specific mortality 1995-8 and 1999-2003, respectively

\begin{tabular}{|c|c|c|c|c|c|c|}
\hline & $\begin{array}{l}\text { All-cause mortality } \\
(\mathrm{n}=222)\end{array}$ & $\begin{array}{l}\text { Violent death } \\
(n=66)\end{array}$ & $\begin{array}{l}\text { Suicide } \\
(\mathrm{n}=45)\end{array}$ & $\begin{array}{l}\text { Violent death other } \\
\text { than suicide }(n=21)\end{array}$ & $\begin{array}{l}\text { Non-violent death } \\
(n=156)\end{array}$ & CVD $(n=61)$ \\
\hline Crude & 2.39 (1.76 to 3.26$)$ & 3.56 (2.12 to 5.97$)$ & $3.1(1.63$ to 5.9$)$ & 4.69 (1.94 to 11.31$)$ & $1.97(1.33$ to 2.90$)$ & $1.68(0.87$ to 3.22 \\
\hline$\%$ reduction of $\mathrm{HR}$ & 60 & 55 & 65 & 33 & 64 & 85 \\
\hline Follow-up 1999 to 2003 & $(n=449)$ & $(n=64)$ & $(n=40)$ & $(n=24)$ & $(n=385)$ & $(n=163)$ \\
\hline Crude & 1.69 (1.33 to 2.15$)$ & 1.42 (0.72 to 2.79 ) & 1.36 (0.57 to 3.23 ) & 1.54 (0.53 to 4.50$)$ & $1.74(1.34$ to 2.25$)$ & 1.73 (1.17 to 2.58 \\
\hline
\end{tabular}

Crude and fully adjusted hazard ratios (HR) with $95 \%$ Cls.

${ }^{*}$ Crowded housing 1960, parental class 1960 Risk use of alcohol 1969, smoking 1969, psychiatric diagnosis 1969, emotional control 1969 and contact with police 1969, psychiatric diagnosis 1973-91, education 1990, socioeconomic position 1990, income 1990-1 and insured sickness absence 1990-1.

Values in bold and italic represent the attenuation of the hazard ratio. 


\section{DISCUSSION}

In this study of stably employed Swedish males born 1949-51, there was a strong association between exposure to unemployment 1992-4 and mortality 1995-2003. These hazard ratios were reduced, but hazard ratios for mortality, externally caused as well as natural, were still significantly increased after adjustment for confounders. The single factor that contributed to the strongest reduction in relative risks was sickness absence 1990-1. There was no statistically significant increased relative risk of mortality 1999-2003 among those unemployed 1992-4 after adjustment for confounders in the analyses.

This study has two notable strengths: first, it is based on reliable measures of employment status (register data). Second, it is a prospective study with longitudinal information on risk factors. A shortcoming of the study is the inclusion of men only. Some studies have shown a higher mortality risk associated with unemployment among men $^{9}{ }^{12}$ while other have found little difference. ${ }^{8}$

In this study employment/unemployment categories are well defined. An issue addressed in several studies is the discrepancy between the unemployed and non-economically active individuals, as confounding of ill health is intrinsic in the former category, while its extent is less known in the latter. ${ }^{13}$ In this study, we have strived to ensure that only those belonging to the workforce were included in the study population. Another design feature is the time at which unemployment is measured. A Finnish study found higher excess mortality among the unemployed in times of low national unemployment than in times of high national unemployment. ${ }^{26}$ It is possible that health-related selection into unemployment is stronger when unemployment rates are low. Alternatively, the effects of unemployment on mortality are stronger in such times. Although a previous study in Sweden ${ }^{9}$ showed slight differences in risks between times of high and low unemployment, we have chosen to measure unemployment in a time of high unemployment, when unemployment ought to be on average more random.

The confounding factors adjusted for in this study were collected from several sources and measured in different time periods. They were selected on the basis that they are associated with risk of unemployment, as well as with mortality. Early childhood factors were collected from father's self-reported status in the 1960 census, when the conscripts were 9-11 years of age, rather than more commonly from retrospective information.

\section{Indirect and direct health-related selection}

Two types of health-related selection may occur. In direct health selection, illness precedes unemployment. In indirect health-related selection, people with risk factors for mortality and morbidity more often lose their jobs. In this study, we had the possibility to adjust the association between unemployment and mortality for several risk factors for mortality measured along the life-course. Psychiatric diagnosis, in 1969 or during 1973-91, and sickness absence 1990-1, may be regarded as indicators of pre-existing illness. The single factor that contributed most to reduce the relative risks found in the crude analysis was sickness absence 1990-1. However, sickness absence is not only an indicator of illness, it is also to some extent an indicator of poor social circumstances.

It is suggested that an increased risk associated with unemployment during the first years, but not later, would indicate a health selection to unemployment due to illness. ${ }^{25}$ The presence of direct health selection to unemployment, it has been argued, would postulate a high relative risk of mortality close to the start of unemployment and a decline in excess risk of mortality among the unemployed over time, as unemployed people with life-threatening illness would die early. In our data, after adjusting for risk factors, a statistically significant relative risk of mortality was found only during the first 4 years of follow-up, while the relative risks were smaller, or reduced to the null, and statistically insignificant, during the last 4 years of follow-up. The remaining increased relative risk of mortality associated with unemployment in the first period may in this scenario be due to unmeasured pre-existing illness. Hence, one possible interpretation of the findings is that most or all of the association between unemployment and mortality was due to health-related selection. However, a decline in relative risk over time does not by necessity mean the presence of direct selection. Rather, it might be due to resilience and positive adaptation; simply, unemployment may have only a short-term effect on mortality. Similarly, the decline in relative risk of mortality might be a result of increased misclassification of the employment/unemployment groups with time: a changing composition due to new cases and re-employment.

\section{Comparison with previous studies}

An association between unemployment and suicide has been shown in several studies. Our study showed that the unemployment-suicide association to a large extent was explained by risk factors measured before exposure to unemployment. No other study known to us has shown the effect of mental disorder on the unemployment-suicide association. In this study, all men were screened for mental disorder and those with symptoms were examined by a psychiatrist. In addition, we also have data from registers on hospitalisation with a psychiatric diagnosis between the ages of 22 and 42 . Hence, our

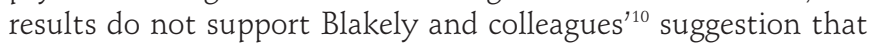
mental disorder is a risk factor exclusively for those who are non-active in the labour force. It also disagrees with the conclusion of Lewis and Sloggett ${ }^{27}$ that mental disorder is entirely on the causal pathway between unemployment and suicide, that is, a mediator and not a confounder.

An association between unemployment and CVD mortality has been presented in other studies. ${ }^{2-6}$ In this study we found a significantly increased relative risk of CVD mortality among those who had been unemployed for 90 days or more. After adjustment for confounding the increased relative risk found in the crude analysis was markedly reduced, and no longer significantly increased. This result is in line with two previous Swedish studies ${ }^{6}$ and contrasts a third by Eliason and Storrie, ${ }^{12}$ which controls for health before unemployment but not individual behaviour. High levels of unemployment seem to be a permanent feature in many countries today. It is important to gather information on the possible health effects.

\section{Conclusion}

Becoming unemployed 1992-4 and experiencing 90 days or more of unemployment was in this study significantly associated with an increased risk of all-cause mortality from natural causes, including CVD, as well as from external causes, both from suicide and from causes other than suicide. Controlling for confounders explained $54-89 \%$ of the excess risk associated with unemployment. Compared with those with no unemployment, those with 90 days or more unemployment experienced more pronounced risks during the first 4 years of follow-up for all outcomes except CVD mortality. After 


\section{What is already known on this subject}

- Unemployment is associated with increased risk of mortality.

- It is not clear if this is causal, or due to some individuals with illness, or risk factors for illness, being more prone to unemployment.

\section{What this study adds}

This study shows that a substantial part of the unemploymentmortality association is due to confounding by health-related risk factors.

controlling for confounders, no statistically significant long-term risks of mortality associated with unemployment remained. Our results suggest that a substantial part of the increased relative risk of mortality associated with unemployment may be attributable to confounding by individual risk factors.

Funding: This study was financed by the Swedish Council for Working Life and Social Research (Project No 2003-0382).

Competing interests: None

Ethics approval: Ethical approval for using the anonymised database was granted by the Karolinska Institute Research Ethics Committee and the Swedish Data Inspection Board.

Provenance and peer review: Not commissioned; externally peer reviewed.

\section{REFERENCES}

1. Martikainen PT. Unemployment and mortality among Finnish men, 1981-5. BMJ 1990;301:407-11.

2. Iversen L, Andersen 0 , Andersen PK, et al. Unemployment and mortality in Denmark, 1970-80. Br Med J (Clin Res Ed) 1987;295:879-84.

3. Morris JK, Cook DG, Shaper AG. Loss of employment and mortality. BMJ 1994;308:1135-9.

4. Moser KA, Fox AJ, Jones DR. Unemployment and mortality in the OPCS Longitudinal Study. Lancet 1984;2:1324-9.

5. Moser KA, Fox AJ, Jones DR, et al. Unemployment and mortality: further evidence from the OPCS Longitudinal Study 1971-81. Lancet 1986;1:365-7.

6. Gerdtham UG, Johannesson M. A note on the effect of unemployment on mortality. $J$ Health Econ 2003;22:505-18.
7. Nylen L, Voss M, Floderus B. Mortality among women and men relative to unemployment, part time work, overtime work, and extra work: a study based on data from the Swedish twin registry. Occup Environ Med 2001;58:52-7.

8. Voss M, Nylen L. Floderus B, et al. Unemployment and early cause-specific mortality: a study based on the Swedish twin registry. Am J Public Health 2004;94:2155-61.

9. Ahs AM, Westerling R. Mortality in relation to employment status during different levels of unemployment. Scand J Public Health 2006;34:159-67.

10. Blakely TA, Collings SCD, Atkinson J. Unemployment and suicide. Evidence for a causal association? J Epidemiol Commun H 2003;57:594-600.

11. Johansson SE, Sundquist J. Unemployment is an important risk factor for suicide in contemporary Sweden: an 11-year follow-up study of a cross-sectional sample of 37,789 people. Public Health 1997;111:41-5.

12. Eliason M, Storrie D. Does job loss shorten life? J Hum Res 2009;44:277-302

13. Kposowa AJ. Unemployment and suicide: a cohort analysis of social factors predicting suicide in the US National Longitudinal Mortality Study. Psychol Med 2001;31:127-38.

14. Hammarstrom A. Health consequences of youth unemployment-review from a gender perspective. Soc Sci Med 1994;38:699-709.

15. Montgomery SM, Cook DG, Bartley MJ, et al. Unemployment pre-dates symptoms of depression and anxiety resulting in medical consultation in young men. Int J Epidemiol 1999;28:95-100.

16. Montgomery SM, Bartley MJ, Cook DG, et al. Health and social precursors of unemployment in young men in Great Britain. J Epidemiol Community Health 1996;50:415-22.

17. Montgomery SM, Cook DG, Bartley MJ, et al. Unemployment, cigarette smoking alcohol consumption and body weight in young British men. Eur J Public Health 1998:8:21-7.

18. Fergusson DM, Horwood LJ, Woodward LJ. Unemployment and psychosocial adjustment in young adults: causation or selection? Soc Sci Med 2001;53:305-20.

19. Luoto R, Poikolainen K, Uutela A. Unemployment, sociodemographic background and consumption of alcohol before and during the economic recession of the 1990s in Finland. Int J Epidemiol 1998;27:623-9.

20. Mortensen PB, Agerbo E, Erikson T, et al. Psychiatric illness and risk factors for suicide in Denmark. Lancet 2000;355:9-12.

21. Heponiemi T, Elovainio M, Manderbacka $\mathrm{K}$, et al. Relationship between unemployment and health among health care professionals: health selection or health effect? J Psychosom Res2007;63:425-31.

22. Caspi A, Wright BRE, Moffitt TE, et al. Early failure in the labor market: Childhood and adolescent predictors of unemployment in the transition to adulthood. Am Sociol Rev 1998;63:424-51.

23. Wadsworth ME, Montgomery SM, Bartley MJ. The persisting effect of unemployment on health and social well-being in men early in working life. Soc Sci Med 1999;48:1491-9.

24. Alexius A, Holmlund B. Monetary policy and Swedish unemployment fluctuations IFAU Working Paper 2008;5:1-33.

25. Larsson D, Hemmingsson T, Allebeck $P$, et al. Self-rated health and mortality among young men: what is the relation and how may it be explained? Scand J Public Health 2002;30:259-66.

26. Martikainen PT, Valkonen T. Excess mortality of unemployed men and women during a period of rapidly increasing unemployment. Lancet 1996;348:909-12.

27. Lewis G, Sloggett A. Suicide, deprivation, and unemployment: record linkage study BMJ 1998:317:1283-6. 